\title{
A Prospective Observational Study between the Value of Sputum Cytology and FNAC of Bronchial Growth in Diagnosing Lung Cancer at Chattogram Medical College Hospital, Bangladesh
}

\author{
Mohammad Moinuddin Chowdhury', Mahmud Hassan Arif², Enshad Ekram Ullah ${ }^{3}$, \\ Abdullah Al Mamun ${ }^{4}$, Mirza Nurul Karim ${ }^{5}$, Rajib Biswas ${ }^{6}$ \\ ${ }^{1,2,3,5,6}$ Assistant Professor, Department of Medicine, Chattogram Medical College, Chattogram, Bangladesh, ${ }^{4}$ Assistant \\ Professor, Department of Paediatrics, Rangamati Medical College, Rangamati, Bangladesh
}

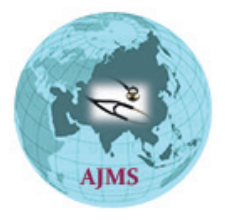

A B S TR A C T

Background: Lung disease is viewed as perhaps the most far reaching and deadly malignancies all throughout the planet. The most seasoned and most crucial technique is based on sputum cytology. The last outskirts for getting sufficient material are fine needle yearning cytology (FNAC) of bronchial development.

Aims and Objective: To relate the meaning of sputum cytology and fine needle goal cytology of bronchial tissue under CT rules for diagnosing cellular breakdown in the lungs.

Materials and Methods: This potential observational investigation was completed by the division of medication in Chattogram Medical College Hospital, Chattogram, Bangladesh. Where data was collected from January 2019 to June 2020. A total of 50 patients with a suspected history, symptoms, and risk profile of having primary lung cancer, as demonstrated by chest radiography and CT scan, were chosen for the research population. Fifty patients with clinical and biochemical verification of suspected. All collected data were coding and input in SPSS-25 for further analysis. Both descriptive and inferential statistics were tested.

Results: Among the 50 patients the vast majority of the patients were 51-60 years of age and the biggest number of the (94\%) patients were male. Sputum cytology is $8 \%$ touchy which isn't steady with different examinations and CT guided FNAC is $94 \%$ sensitive.

Conclusion: A definitive point of picture guided histological or cytological examination is to stay away from unnecessary thoracotomy and accomplish a particular determination with sensible exactness and least results. So, in this examination we found that sputum cytology is $8 \%$ delicate which isn't steady with different investigations and CT guided FNAC is $94 \%$ touchy to last histological analysis of lung cancer. The discoveries recommended that CT guided FNAC discovered to be protected, feasible and viable.

Key words: Sputum cytology; CT guided FNAC; Lung cancer

\section{INTRODUCTION}

Cancer is called after the location where it first appeared. It might be cells lining the bronchi or cells in any area of the lung, including the bronchioles and alveoli. It is well recognized that a cell is a fundamental unit of life, and
http://nepjol.info/index.php/AJMS DOI: 10.3126/ajms.v12i9.37250

E-ISSN: 2091-0576

P-ISSN: 2467-9100

Copyright (c) 2021 Asian Journal of Medical Sciences

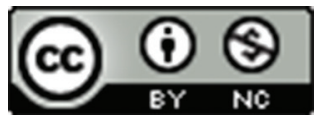

This work is licensed under a Creative Commons Attribution-NonCommercial 4.0 International License. 
procedures alone. These strategies get cell material reasonable for an unequivocal determination. The utilization of lung cytology has advanced over the most recent couple of years. ${ }^{2}$ The most seasoned and most basic technique depends on sputum cytology, which depends on the unconstrained shedding of malignancy cells. A basic, useful method which has demonstrated helpful in recommending, developing or affirming the conclusion of carcinoma of the lung is sputum cytology. Rapid breakthroughs in molecular biology, pathology, bronchology, and radiology have offered a reasonable basis for improving outcomes during the previous few decades. These developments resulted in more accurate documenting of morphological alterations in the bronchial epithelium prior to the emergence of clinically visible invasive lesions. ${ }^{3}$ The cytologic examination of sputum is a valuable expansion to the systems for the analysis of carcinoma of the lung. Sputum assessment for malignant growth cells remained the sheet anchor of conclusion for over 60 years. It keeps on being utilized in light of the simplicity of test buy. ${ }^{4}$ There are a few papers that show a progression of three adequate examples will give sufficient proof for a conclusion of bronchogenic carcinoma in about $80 \%$ of focal injuries and half of fringe sores. ${ }^{5}$ However, the fundamental issue is powerlessness to gather adequate sputum in a large portion of the patients. After bronchoscopy, most patients will sniffle and expectorate some sputum and there are a couple of papers showing the symptomatic yield of post bronchoscopy sputum in fringe cellular breakdown in the lungs, especially the quick post bronchoscopy sputum yet these results were variable. ${ }^{6,7}$ Since this technique is straightforward, practical and nonobtrusive it is likely prompt post bronchoscopy sputum will be useful in the finding of fringe lung carcinoma. ${ }^{1}$ The last wilderness for getting adequate material is fine needle goal cytology (FNAC) of bronchial development. This is an obtrusive cycle and ought to subsequently be dependent upon normal audit. FNAC is the solitary methods for determination of danger and it tends to be used with certainty to choose treatment modalities and to keep away from superfluous medical procedures in patients with lung malignancies ${ }^{8}$ to neighborhood factors or the patient's overall condition, FNAC confirms the determination and clarifies the tumor type. This is valuable in choosing the remedial strategy in patients in whom consequences of bronchoscopy and sputum cytologic investigation are not indicative, ${ }^{9}$ from the institute of general and thoracic pulmonary surgery. ${ }^{10}$ In patients for medical procedure with uncertain lone pneumonic knob (SPN), i.e., without clear radiologic indications of danger or benevolence,${ }^{11}$ for whom consequences of routine cytologic investigations are typical, revelations from FNAC might be symptomatic. ${ }^{12}$ It is explicitly in these cases that the successful value of FNAC is addressed, additionally on the grounds that new video thoracoscopic techniques are accessible with which finding can be made and treatment acted in a solitary negligibly obtrusive careful strategy. ${ }^{13,14}$ We along these lines played out an imminent report to analyze the worth of sputum cytology and FNAC of bronchial improvement in recognizing cellular breakdown in the lungs.

The diagnostic and therapeutic efficacy of a process depends on its competence, accessibility, and patient compliance. The primary use of these methods is in the detection of lung cancer, followed by infective pathology. These approaches cause the least amount of pain and consequences for the patient. Laryngospasm, bronchospasm, hypoxia, infection, bleeding, aspiration, and cardiac arrhythmias are common consequences. The study by Vijay et al. revealed around 0.5 percent serious problems and 0.8 percent mild problems. ${ }^{15}$ Sputum cytology is employed since it is cost effective to have it tested on a regular basis. Sputum samples are easily obtained since people cough. In contrast to other procedures, some people may be allergic to the fluid injected into the body during a CT scan. Additionally, some people may find it difficult to be in the tube-like structure utilized for Magnetic Resonance Imaging (MRI). ${ }^{16}$

\section{AIMS AND OBJECTIVE}

To compare the value of sputum cytology and FNAC of bronchial growth in diagnosing lung cancer infection.

\section{MATERIALS AND METHODS}

The current study was a prospective observational study, conducted in the department of Medicine, Chattogram Medical College Hospital (CMCH), Chattogram, Bangladesh for a period between January 2019 to June 2020. A total number of 50 patients whose suspected history, symptoms and risk profile of having primary lung cancer which is evidenced by chest radiography and CT scan, suggestive of malignancy considered for the study population. Sample were collected through purposive sampling as per inclusion and exclusion criteria. Prior to the study the ethical clearance was obtained from the Institutional Ethical Committee, Chattogram Medical College Hospital $(\mathrm{CMCH})$, Chattogram, Bangladesh.

Inclusion Criteria: All the patients' age more than 18 years old and having no prior confirmed diagnosis for current suspicious lung tumor and FEV1 at least 40\% predicted to be included in the study.

Exclusion criteria: But the patients who are unwilling to give consent, seriously ill patient with co-morbid conditions 
like LVF, COPD with respiratory failure, severe SVC obstruction etc. distant metastasis, previously diagnosed bronchial carcinoma is excluded from the study.

Statistical Analysis and Data Visualization: Both of qualitative and quantitative data were collected by using a pre designed questionnaire. The questionnaire was prepared reviewing literature and consulting with medical research experts. After acceptance of research proposal by ethical review committee $\mathrm{CMCH}$ all procedures were started. All collected data were coding and input in SPSS25 for further analysis. Both descriptive and inferential statistics were tested. Descriptive statistics included frequency distribution, percent, mean, standard deviation; graph, tables, figures and inferential statistics included correlation, regression, ANOVA etc. as well.

\section{RESULTS}

Figure 1 shows the age distribution of the patients, where most of the patients belong to 51 to 60 years age group.

Figure 2 shows the sex appropriation of the patients, where the majority of patients $94 \%$ were male.

Table 1 shows the sputum status provided by the patients, where $38(79.17 \%)$ examples had been acknowledged as acceptable for cytological evaluation, as alveolar macrophages or bronchial epithelial cells were available in the sputum. Then again, 25\% examples had been dismissed as actually unacceptable.

In Table 2 shows the sputum sensitivity of the patients, where only $8 \%$ specimens had been diagnosed.

Table 3 shows the Histological type of Ca-Lung done by CT-guided FNAC of the patients.

\section{DISCUSSION}

The most widely recognized age bunch influenced by $\mathrm{Ca}$ lung in this investigation was in the middle 51 to 60 years

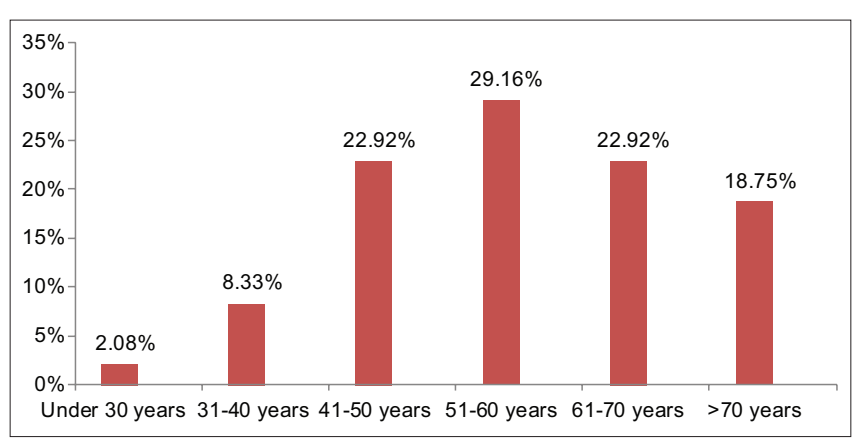

Figure 1: Age distribution of the patients
(29.17\%). Next normal age bunch in the middle of 41 50 years $(22.92 \%)$ and $61-70$ years $(22.92 \%)$. Le Roux inspected 4000 patients and found $15 \%$ of patients below the age of 50 years and $10 \%$ over the age of 70 years. A total of $75 \%$ of the patients were in the $60-70$ years. ${ }^{17}$ In this specific examination 47 patients were male and just 3 patients were female giving male-female proportion 15:1. In Bignal J R et al., study male-female proportion was 10:1 ${ }^{18}$ Silverberg E and Lubera UJ et al., 1989, showed that male-female proportion in 1960 was 7:1 yet in 1988 it had tumbled to $2: 1 .^{19}$ Fifty patients under went for cytological assessment of sputum for harmful cell, an eventual outcomes of essential bronchial carcinoma had been made just $4(8 \%)$ patients, there were 3 patients with positive cytology and 1 patient with dubious cytology. Every one of the patients presented a sufficient and agreeable sputum tests. All the above examinations show the expanding rate.

The male female proportion in our investigation isn't steady with any of the above examinations. This might be because of the way that this investigation was little and specific, high smoking rate in men and low in ladies in our country and general propensity of our female patients to keep away from emergency clinic affirmation. In another Study from the Department of Respiratory Medicine, Kings Cross Hospital, Dundee, an eventual outcome of bronchial carcinoma had been made in 377 patients. There were 225 patients $(59.7 \%)$ in the positive gathering also 208 patients with positive cytology and 17 dubious with cytology. ${ }^{7}$ Transthoracic FNAC under CT direction and obsessive assessment of suctioned materials was done in this examination. In just 6\% cases CT guided FNAC flopped because of profound situated and midway positioned lung injury which is low. Forty four percent of squamous cell carcinoma, 28\% adenocarcinoma, 16\% little cell carcinoma and $6 \%$ inadequately separated carcinoma were found in this examination too. In this investigation conclusive cytodiagnosis was made in 50 patients bringing about a

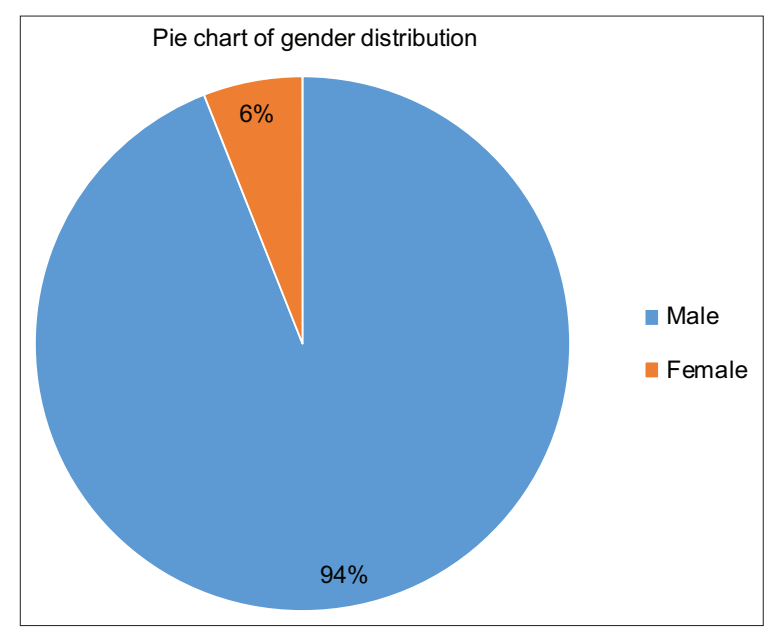

Figure 2: Gender distribution of the patients 


\section{Table 1: Sputum status of the patients}

\begin{tabular}{lcc} 
Status of sputum & Number of cases & Percentage \\
\hline Satisfactory & 38 & $79.17 \%$ \\
Unsatisfactory & 12 & $25 \%$ \\
\hline
\end{tabular}

Table 2: Sputum sensitivity of the patients

\begin{tabular}{lcc}
\hline Type & Number of cases & Percentage \\
\hline Squamous cell carcinoma & 2 & $4.00 \%$ \\
Adenocarcinoma & 1 & $2.00 \%$ \\
Small cell carcinoma & 1 & $2.00 \%$ \\
Undiagnosed & 46 & $92.00 \%$ \\
Total & 50 & $100 \%$ \\
\hline
\end{tabular}

\begin{tabular}{lcc}
$\begin{array}{l}\text { Table 3: Histological type of Ca-Lung done by } \\
\text { CT-guided FNAC }\end{array}$ & $\begin{array}{l}\text { Number } \\
\text { of cases }\end{array}$ & Percentage \\
\hline Histological Type & 22 & $44 \%$ \\
& 14 & $28 \%$ \\
\hline Squamous cell carcinoma & 8 & $16 \%$ \\
Adenocarcinoma & 3 & $6 \%$ \\
Small cell carcinoma & 3 & $6 \%$ \\
Poorly differentiated carcinoma & 50 & $100 \%$ \\
Undiagnosed & & \\
Total & & \\
\hline
\end{tabular}

symptomatic exactness of $94 \%$. Transthoracic FNAC of the lung was $93.4 \%$ positive for danger in a research by K.B. Than et al. This examination was additionally showed 49.4\% adenocarcinoma, 16\% squamous cell carcinoma, $22.5 \%$ metastatic and others. ${ }^{20}$ Sputum cytology indicated a sensitivity of 3.60 percent for neoplastic lesions and an 8.99 percent sensitivity for nonneoplastic lesions. In their study, Jamal A et al., emphasized proper sampling, a fundamental flaw in sputum diagnosis that was likewise the most relevant component in the current study. ${ }^{21} \mathrm{~A}$ definitive objective of picture guided histological or cytological investigation is to stay away from pointless thoracotomy and accomplish a clear conclusion with sensible precision and an extremely low result. So, in this investigation we found that sputum cytology is $8 \%$ delicate which isn't reliable with different examinations and CT guided FNAC is 94\% touchy to last histological finding of Ca-lung which is predictable. The outcomes proposed that CT guided FNAC discovered to be protected, possible and successful.

\section{CONCLUSION}

This examination was done on little, chosen conceded patients in branch of medication, Chittagong Medical College Hospital. A definitive objective of picture guided histological or cytological exploration is to stay away from pointless thoracotomy and accomplish an unequivocal finding with sensible precision and extremely low results. So, in this investigation we found that sputum cytology is $8 \%$ touchy which isn't predictable with different examinations and CT guided FNAC is 94\% delicate to last histological analysis of Ca-lung. The outcomes recommended that $\mathrm{CT}$ guided FNAC discovered to be protected, plausible and compelling.

\section{REFERENCES}

1. Wongsurakiat $\mathrm{P}$, Wongbunnate $\mathrm{S}$, Dejsomritrutai $\mathrm{W}$, Charoenratanakul S, Tscheikuna J, Youngchaiyud P, et al. Diagnostic value of bronchoalveolar lavage and postbronchoscopic sputum cytology in peripheral lung cancer. Respirology. 1998;3(2):131-137. https://doi.org/10.1111/j.1440-1843.1998.tb00111.x

2. Bhatia A, Singh N and Arora VK. A perspective on cytology of lung cancer. Indian J Chest Dis Allied Sci. 2004;46(2):81-83.

3. Jack $\mathrm{Cl}$, Sheard JD, Lippitt B, Fromholtz A, Evans CC and Hind CR. Lung cancer in elderly patients: the role of induced sputum production to obtain a cytological diagnosis. Age Ageing. 1993;22(3):227-229. https://doi.org/10.1093/ageing/22.3.227

4. Tanaka T, Yamamoto M, Tamura T, Moritani Y, Miyai M, Hiraki S, et al. Cytologic and histologic correlation in primary lung cancer. A study of 154 cases with resectable tumors. Acta Cytol. 1985;29(1):49-56.

5. Funahashi A, Browne TK, Houser WC and Hranicka LJ. Diagnostic value of bronchial aspirate and post bronchoscopic sputum in fiberoptic bronchoscopy. Chest. 1979;76(5):514-517. https://doi.org/10.1378/chest.76.5.514

6. Trevisani L, Pazzi P, Sartori S and Potena A. Value of washings and brushings at fiberoptic bronchoscopy in the diagnosis of lung cancer. Thorax. 1991; 46:74-76.

https://doi.org/10.1136/thx.46.1.74-b

7. Liu J-J, Ding J, Kowal AS, Nardine T, Allen E, Delcroix J-D, et al. BPAG1n4 is essential for retrograde axonal transport in sensory neurons. J Cell Biol. 2003;163(2):223-229.

https://doi.org/10.1083/jcb.200306075

8. Kaufman M, Schwartz $I$ and Weissberg D. Fine-needle aspiration biopsy in diagnosis of pulmonary masses. Am Surg. 1987;53(6):339-341.

9. Zarbo RJ and Fenoglio-Preiser CM. Interinstitutional database for comparison of performance in lung fine-needle aspiration cytology. A College of American Pathologists Q-Probe Study of 5264 cases with histologic correlation. Arch Pathol Lab Med. 1992;116(5):463-470.

10. Groskin SA. Peripheral mass lesions in the lung. $3^{\text {rd }}$ ed. St. Groskin SA, Heitzman S, editors. Louis: Mosby-Year Book; 1993.

11. Rio FG, Lobato SD, Pino JM, Atienza M, Viguer JM, Villasante $\mathrm{C}$, et al. Value of TC-guided fine needle aspiration in solitary pulmonary nodules with negative fiberoptic bronchoscopy. Acta Radiol. 1994; 35:478-480. https://doi. org/10.1177/028418519403500517

12. Charing MJ, Stutley JE and Padley SPG. The value of negative needle biopsy in suspected operable lung cancer. Clin Radiol. 1991; 44:147-149. https://doi.org/10.1016/S0009-9260(05)80856-6

13. Mack MJ, Hazelrigg SR, Landreneau RJ and Acuff TE. Thoracoscopy for the diagnosis of the indeterminate solitary pulmonary nodule. Ann Thorac Surg. 1993;56(4):825-830. https://doi.org/10.1016/0003-4975(93)90339-J

14. Le Roux BT. Bronchial carcinoma. Thorax. 1968;23(2):136-143. 
https://doi.org/10.1136/thx.23.2.136

15. Bignall JR. Bronchial carcinoma; survey of 317 patients. Lancet. 1955;268(6868):786-790.

https://doi.org/10.1016/S0140-6736(55)90485-2

16. Silverberg E, Lubera JA. Cancer statistics, 1988. CA Cancer J Clin. 1988;38(1):5-22.

https://doi.org/10.3322/canjclin.38.1.5

17. Others. Collecting a sputum specimen Geisinger medical laboratory. Collecting a sputum specimen Geisinger [Internet]. Pdfslide.net. Unknow; 2019 [cited 2021 Jun 14]. Available from: https://pdfslide.net/documents/collecting-a-sputum-specimengeisinger-medical-laboratory-collecting-a-sputum.html

18. Ojha P, Madan R and Bharadwaj R. Correlation between sputum and bronchoscopy-guided cytology (bronchoalveolar lavage fluid, transbronchial needle aspiration, and bronchial brush) with bronchial biopsy in the diagnosis of pulmonary pathology. Arch Med Health Sci. 2019;7(1):25. https://doi.org/10.4103/amhs. amhs_135_18

19. Tomar V, Vijay N, Nuwal P and Dixit R. Comparative study of bronchoalveolar lavage, bronchial brushing, and FNAC in diagnosing malignant neoplasms of lungs. J Cytol. 2016;33(4):210-213. https://doi.org/10.4103/0970-9371.190448

20. Kumar $\mathrm{V}$ and Sharma $\mathrm{H}$. Extraction of nuclear region from sputum images through pixel classification for early lung cancer detection. International Journal of Computer Applications. 2013;72(22):35-39.

21. Jamal A and Mansoor I. Sputum cytology-an underutilized diagnostic tool: A single Institute experience. Life Sci J. 2012; 9:681-685

\footnotetext{
Authors Contribution:

MMC, MHA- Study conception and design; MHA, A AI M- Data collection; MC, MHA, MNK- Analysis and interpretation of results; RB, MC,MHA- Draft manuscript preparation; All authors reviewed the results and approved the final version of the manuscript.
}

\section{Work attributed to:}

Chattogram Medical College Hospital, Chattogram, Bangladesh.

Orcid ID:

Dr. Mahmud Hassan Arif - (10) https://orcid.org/0000-0002-0860-5149

Source of Support: None, Conflict of Interest: None. 